\title{
EL ODIOSO DE MORA
}

\author{
María Amoretti Hurtado
}

\begin{abstract}
The following article is an attempt to provide a new and positive analysis of Virgilio Mora's literary work, which, for many years, has suffered the rejection of Costa Rican society due its straightforwardness and the controversy it raises.
\end{abstract}

Virgilio Mora es un tico desterrado, enamorado de Nueva York según lo confiesa constantemente, pero que sin embargo vive anclado en el recuerdo de un Desamparados que desapareció en el ventolero de los últimos 35 años. Durante todos esos años de exilio voluntario no ha dejado de escribir con una pluma que recoge, testimonia, lo que fue y está siendo esta sociedad costarricense, sin tapujos, sin eufemismos. Este artículo es el primero de una serie de trabajos que pretenden ofrecer un examen bastante prolijo de la producción de este autor .

En este primer trabajo se pretende hacer una introducción y un comentario general, sobre el autor y su obra; en él se destacan los rasgos más relevantes de su estilo, el propósito global intuido y una motivación que logre llamar la atención del lector, sobre todo el nacional, e iniciar así una operación resarcitoria del inexcusable silencio con que se han castigado los escritos de Mora.

Ciertamente un tico disconforme, intenso, raro espécimen. Ese es Mora. Hablar de Mora o de su obra siempre es riesgoso. Hombre y obra, la misma cosa, controversiales. No se puede hablar de ninguno de los dos con impunidad. Siempre se corre el riesgo de una de dos alternativas: la aprobación entusiasta o el gesto de repugnancia. A Mora se le quiere o se le aborrece. No hay términos medios. A su obra se le admira o se le tira al basurero. Con cualquiera de los dos, el hombre o la obra, no hay posible indiferencia. Cuestión de gustos, cuestión de preferencias estéticas, cuestión de espacios sociales, cuestión de visión de mundo, cuestión de cuánto estamos dispuestos a oír o de cuánto estamos dispuestos a ignorar de alguien que sí tiene cosas que contar, como me dijo una vez el maestro Joaquín Gutiérrez refiriéndose a la obra de Mora. Pero también -y sobre todo, diría yo con énfasis- cuestión de interpretación, cuestión de la dimensión significa que usted elija, de su propia filosofía del lenguaje, de su propia teoría del valor semántico, cuestión del modo cómo usted entiende el significar y desde qué nivel. Yo voy a hablar, obviamente, desde mis propias elecciones y asumo en ello toda la responsabilidad de mi evaluación crítica. 
El libro, cuya presentación es el propósito de esta reunión, es una especie de fresco que repertoria las inquietudes existenciales y artísticas más asediantes a lo largo de toda su producción que, dicho sea de paso, es una de las más abundantes que yo conozco en la narrativa costarricense contemporánea. Mora ha escrito inumerables cuentos y, sobre todo, muchas novelas, en los últimos años. El gran problema es que de la totalidad de sus obras, sólo hay disponible en circulación apenas un $20 \%$. Muchas de ellas, si bien tienen su publíquese aprobado en la Editorial de la Universidad de Costa Rica, se encuentran todavía haciendo fila, esperando su tumo de edición.

Les decía que para mí hoy hacemos un acto de justicia, porque a pesar de esta labor disciplinada, incansable, imparable por escribir, y escribir a pesar de todo: a pesar de no ver sus textos editados con la prontitud requerida, a pesar de su trabajo en los Hospitales de New York, a pesar de la distancia que lo separa de aquellos para quienes escribe, a pesar de sus esfuerzos - logrados la mayor parte de ellos- por desbordar los estrechos límites de la experimentación formal en la literatura costarricense; a pesar de todo eso, Mora no ha encontrado o no ha podido caminar por los trillos del reconocimiento nacional en este país. No obstante, paradojas de la vida, ha sabido despertar el interés en medios académicos franceses, venezolanos, ecuatorianos, a donde he tenido la oportunidad de exportar algunas muestras de su obra.

Otros de sus manuscritos esperan dictamen en alguna comisión editorial. Hay que reconocer que para editar a Mora hay que tener coraje y una disposición de espíritu muy abierta. La Editorial de la Universidad de Costa Rica lo ha tenido, a pesar de las quejas del autor por la lentitud con que sus manuscritos salen a la luz pública. Tenía que ser la Editorial de una Universidad. Mora ha tenido mejor suerte en los medios académicos, eso es definitivo.

He dicho que su obra es una de las más prolíficas en la narrativa actual de este país, pero en realidad, la verdad sea dicha, Mora no ha escrito mucho. Quiero decir, antes de que se les acolochen a ustedes las ideas y me comiencen a pensar como un nudo de incoherencias, quiero decir que Mora siempre escribe de lo mismo. Lo que habría que decir aquí es que Mora lo que hace es reescribir y reescribir la misma historia, una historia que me envió hace un par de meses y que no llena la mitad de una página. El cuento de Luis y Luisita, un par de jóvenes que se casan sin saber que son hermanos. Esa es su historia, su tema, su leit motif, su isotopía, su genotexto, su centro programador, dirían los técnicos. Lo que se mueve, lo que cambia, se transforma y evoluciona sin parar es la forma. La historia es lo de menos, me dijo un día Mora, lo que realmente importa es cómo contarla. Su obra es una obra polimorfa. Y qué buen narrador es, que yo le he estado escuchando la misma historia durante diecisiete años y se la seguirfa escuchando por otros diecisiete. En sus libros las páginas se voltean veloces hasta desaparecer, se desintegran en las manos y los ojos se hacen oídos: el saber integrar el sabor, el ritmo, la gracia de la narración oral es uno de sus mejores logros y una necesidad para la urgencia comunicativa de Mora. Ya veremos porqué.

Pero la historia no es lo de menos, me vuelvo a contradecir, ya se irán acostumbrando, mi coherencia debe estar en alguna parte, en algún otro nivel. La historia también significa. Intriga. ¿Por qué esa obsesión por el incesto? ¿Por la castración? ¿Por la sexualidad pervertida? ¿Por el exceso y la represión sexual al mismo tiempo?

Deformación profesional responderían algunos. Porque Mora es Médico psiquiatra y neurólogo de profesión. No falta razón a esa respuesta, pero personalmente pienso que la sexua- 
lidad y la perversión que caracteriza la obra de Mora no es más que una forma de maniobrar, una forma de producir su tema genuino: la subjetividad. Obviamente es el discurso y la práctica psicoanalítica la que lo conduce ahí: a la sexualidad y al mundo de sus patologías. Pero el hecho de hablar esto, de escribir esto y de escribirlo con la risa maligna con que lo escribe, es otro signo que no logra ser explicado por esa respuesta.

Decir la palabra prohibida en una práctica discursiva que no es exactamente la del psiquiatra que describe una nosografía, que diagnostica, sino la del que cuenta sobre estas cosas de la vida con la idea de ver hasta dónde aguanta usted, hasta dónde es usted capaz de soportar un tour por el mundo subterráneo de su sociedad, por las cloacas nauseabundas de su mundo, tiene algo de agresión. Cuán lesionado se sienta usted, depende de cuán dispuesto esté usted para experimentar, sufrir, el vértigo de un "bungie jumping" de conciencia que provoca ver el cuerpo

Decía Foucault, al explicar el significado histórico del surgimiento del psicoanálisis, que a partir de Freud la sexualidad se convierte en una tecnología de la subjetividad, pues es aquello que hay que interpretar para llegar a la verdad de quién soy. La verdad legítima hoy, el discurso verdadero sobre uno mismo, es el discurso de la sexualidad. Por su medio el sujeto se objetiva para sí mismo y para los otros a través de ciertos procedimientos precisos de gobierno (entre ellos, el control de la vigilancia y el castigo). Así, la sexualidad se convierte entonces en un sistema de interdicción que se empareja con la obligación de un cierto desciframiento de uno mismo. Es una especie de oráculo de Delfos de la subjetividad, pero también, gracias a los procedimientos de gobierno implicados en el proceso de objetivación del yo, la sexualidad es también una tecnología de dominación de los demás. Sexual Power. La sexualidad es una forma de gobernabilidad del individuo en relación consigo mismo y en relación con los demás. Ese es el presupuesto sobre el que se basa la lógica de la sexualidad como código productor de la individualización de los personajes de Mora y su mundo.

Este poder de la sexualidad como tecnología de la subjetividad explica también el porqué la sexualidad se relaciona de una forma extraña y compleja con la prohibición verbal. Algunos rechazan. la obra de Mora precisamente porque su expresión les resulta impúdica, desvergonzada y desenfrenada. Por ello mismo la obra de Virgilio Mora es candidata a encabezar la lista de los narradores malditos de este país; por su empeño en hablar de la concupiscencia y por untar de lujuria las páginas de sus historias. Narrador proscrito por enunciar la palabra prohibida; hereje social, por practicar la heterodoxia del pensar distinto y por ejercer blasfemáticamente el santo oficio del escribir y por, encima de todo esto, por reírse con una risa maligna, muy consciente del estremecimiento que causa retar la contraloría general de los discursos y socavar de todos los discursos posibles, precisamente aquel que es el discurso fundante del orden social y de la constitución del yo, de un discurso que es la medida de los grados de sometimien-
to del sujeto a la normalidad.

Su historia no es, pues, en realidad la del incesto, sino la historia de la constitución de una subjetividad, la saga de un yo que busca su propia medida, fuera de toda convención. Tampoco es, entonces, la historia de Luis y Luisita, sino la de Polo Moro, el doble de Mora en El final del comienzo, una de sus mejores novelas, una pieza arquitectónicamente magistral en la historia de la narrativa costarricense. En esta autobiografía literaria, y subrayo literaria, Polo Moro, el yo autobiografiado, se independiza del yo autobiografista y se inicia un diálogo que no 
es otra cosa que la dramatización del conflicto entre un yo en sí, psicoideológico, y un yo real que se ha abierto paso entre las constricciones de los convencionalismos a base de experimentar sin recato alguno cuanta posibilidad le abre el contexto, en un proceso de mundanización que no rechaza nada, ni el mundo, ni el demonio, ni la carne; con la complicación adicional, y en eso reside el dramatismo mencionado, de que es dif́cil saber cuál es cuál. ¿Quién es el sujeto real: Moro o Mora? Yo no lo sé y esto es buena seña. Voy a explicar porqué.

Según el canon estético que rige hoy el gusto y el criterio en materia literaria, la literatura es un mecanismo productor de significación que potencia hasta sus extremos los códigos lingüistico-sociales para crear una intensificación significativa. Los códigos lingüístico-sociales se violan y la ambigüedad que esta alteración desencadena abre la obra a oscilaciones de sentido. La interpretación de este sentido en fuga es lo que hace posible la participación creativa del receptor y las estrategias para desbaratar el sentido y hacerlo dispersarse en miles direcciones, es lo que ha divertido y hecho sudar al escritor. Pero algo más de placer obtiene el creador además de construir, a pesar de esa dispersión del significado, una coherencia cuya totalidad es siempre frágil y provisional asida, como irremediablemente estará siempre, a una transa lección personal y dialéctica entre el lector y el escritor.

Ese otro placer del que hablábamos lo describe el esteta alemán Worringer. Según él, el acto creador comienza por un desprendimiento del sí. Para Worringer, el goce estético es un goce objetivado del sí. Gozar estéticamente es entonces gozar de sí mismo en un objeto sensible, distinto de sí y sentirse en empatía con él.

Mora crea a Moro, Polo Moro; el tipo de Desampa que después de sacar el Bachillerato en el Liceo, se fue a estudiar medicina a Méjico en los años cincuenta; que regresó, hizo desastres y se fue para los Estados Unidos a ver si se componía, pero fue peor la cosa.

Esta creación de Mora no es otra cosa que la objetivación de sí mismo; pero le resulta un sí tan distinto de sí mismo que, una vez terminado el libro y después de una confrontación bien fuerte con él en algunas de sus páginas, se le subleva y escapa de la computadora. Mora se encontraba de vacaciones en Bordeaux y debe recorrer calles, bares y cafés para recuperar a Moro y al resto de sus personajes, pues todos ellos habían sido liberados por Polo, como venganza por las tremendas discrepancias que el escritor redactó sobre su persona y lo que Moro cree que él es realmente.

Polo se vuelve inmanejable para Mora. Dentro de la computadora se oculta de window en window, espía al autor en su trabajo, le viola y altera sus escritos. A Mora no le queda otra que transar con su yo objetivado, el otro, y escribir con él Mano a Mano, otra de sus novelas.

Este levantar al personaje de la página, como suele decir Virgilio Mora, lo había hecho don Miguel de Unamuno por primera vez en Niebla. Nada nuevo entonces. Pero Mora va más allá. Va hasta el extremo de escribir su siguiente novela en asocio con su doble, en coautoría con Polo, su otro yo. Es de imaginar los cólicos cerebrales que sufriría Worringer tratando de describir algo así como un creador que goza con un desprendimiento del sí que se desprende de otro desprendimiento del sí.

A este alejamiento del yo para contemplarse en un sí objetivado, que es un otro, un tú, Bajtín lo llama exotopía. Pues bien, en El final del comienzo y luego en Mano a Mano, Mora produce, ficcionaliza, la perfecta exotopía bajtiniana, base de la creación literaria, modelo ideal de comunicación, según el maestro ruso, porque en ella se ilustra en toda su plenitud el principio dialógico. 
La relación Mora-Moro es, por otra parte, el despliegue paradigmático de la relación buberiana. Según Martín Buber, el yo del hombre es doble, pues se bifurca entre el yo-tú y el yo-ello. Así, para el hombre ante el mundo sólo son posibles dos actitudes, dos tipos de relación extremadamente diferenciadas: la que se da en la palabra primordial yo-tú y que sólo puede ser pronunciada por el ser entero; y la que se da en la palabra principio yo-ello y que jamás puede ser pronunciada por el ser entero.

Entre ese yo-tú, entre Mora y Moro, ¿cuál es el sujeto real? , nos preguntábamos hace un rato. Y sigo sin saberlo. Creo que ni el propio autor lo sabe : cuánto de él hay en Moro, ni cuánto de Moro hay realmente en Mora; porque Mora-Moro no son una unidad. El yo real no es exactamente una síntesis, sino un juego de verdad que se da en la relación misma Mora-Moro. Ellos establecen una relación en la que los dos se asumen el uno al otro en una presencia desalienada, sin absorción el uno del otro, y se constituyen sólo en esa relación y por ella: Mora, a partir de Moro; Moro, a partir de Mora. Las implicaciones de este fenómeno son obvias para un estudio del género autobiográfico, además de ofrecer material suficiente para una discusión de la ontología buberiana y la antropología filosófica propuesta por Bajtín.

La creación de Polo Moro en el relato de Mora viene a demostrar que el ser se crea continuamente, y que se constituye en la voz interior dialógica del yo, su interlocutor interior. Asf́ como el signo se define por algo distinto de sí mismo, el sujeto se constituye por otro distinto de sí mismo. No es difícil pensar entonces que el ser del hombre no es otra cosa que una comunicación, una comunicación profunda. Ser es comunicar. Por eso escribe Mora.

Cada relato de Virgilio es un intento más por crear una forma diferente; cada relato suyo es un laboratorio en el que se investigan formas de comunicar. Comunicar es la palabra clave para entender a Mora.

Bajtín está convencido de que la estructura de la comunicación ideal está contenida en la comunicación literaria. Bajtín cree que en la literatura está la formula mágica, el secreto misterio de la comunicación perfecta, la que va a permitir la creación de un sujeto capaz de romper la barrera que impide el encuentro con el otro. Mora escribe aguijoneado precisamente por esa esperanza.

Volviendo al caso Mora-Moro, decíamos que esta estrategia le permite al texto fundar una ambigüedad irresoluble, garantía de una apertura y falta de acabamiento que hacen de $E l$ final del comienzo una obra muy contemporánea desde el punto de vista del paradigma estético vigente en nuestros días. Pero el extremo hacia el que el escritor empuja este inacabamiento es, según mi opinión, algo más que inédito en el panorama de las letras hispanas; se trata del hecho de que la ficción ficcionalice al propio autor y reficcionalice a Polo en la siguiente novela; porque Mano a Mano es una novela cuyos derechos de autor la jurisprudencia vigente tendría graves conflictos en catalogar, escrita, como dice estar, por dos seres de papel que se han encargado lindamente de confundir las esferas, siempre tan respetables, entre ficción y realidad.

Por eso, ya yo tampoco ni siquiera sé quién me escribe los faxes que recibo todos los lunes por la mañana. Si es Polo o es Virgilio. Y ese es otro de los fenómenos interesantes en la obra de este autor: en ella el límite entre la ficción y la realidad quedan totalmente aniquilados, al punto que una suspensión del fluido eléctrico en la casa de uno de los personajes, pone en peligro todo el proceso de escritura, a menos que el escritor sea lo suficientemente veloz para ordenarle a tiempo a su computadora el "save" del material que lleva escrito. 
Pero, en estas condiciones, el escritor no es el único que corre el riesgo de un desquiciamiento; el lector también se encuentra amenazado, sobre todo cuando descubre que el texto lo ha desintegrado, que ya no existe, porque el que está leyendo no es él, porque el lector es otro; él no es más que alguien que oye. El texto lo ha transformado simplemente en un oidor. Esto sucede en el último de los relatos de Mora, la novela titulada $A$ flote, la cual me alegro de que esté protegida por la regla $\mathrm{F}$ (regla de la ficcionalidad del contrato narrativo), por el principio de ambigüedad y por la relatividad interpretativa correspondiente a su condición de obra abierta. Mora necesitará de toda esta inmunidad literaria, porque alli se pone más odioso que nunca.

Estarán en un verdadero problema quienes ilusamente intenten ver referencias en la obra de Mora, por más evidentes que ciertos datos parezcan. Ese límite no existe allí, tan es asi, que Mora tiene que terminar aceptando el asocio de Moro, su personaje, y escribir hombro a hombro Mano a mano; porque de no haberlo hecho así, Moro hubiera logrado subvertir al resto de sus personajes, incluida su abuelita, la abuela de Mora, la viejecita de luto que vive encerrada al lado de su fogón en una casa de adobe, en una esquina del centro de Desamparados y a quien el autor sorprende horrorizado disfrutando de una fiesta orgiástica organizada por Moro, para todos sus congéneres de papel, hijos de la pluma (¿o debería decir computadora?) de Mora.

¿Buscar referencias a la realidad en la obra de Mora? Tiempo perdido, pérdida de foco, así no se puede entrar a las novelas de Mora, máxime si se tiene en cuenta su humor perverso, logrado a base de una ironía caricaturizante que burla cualquiera de las marcas referenciales que usted haya creído percibir.

Definitivamente, en este caso cualquier parecido de la realidad con la ficción es mera coincidencia. La primera ilusión referencial es el mencionado caso Mora-Moro; al complicarse de ese modo tan extraño la instancia narrativa misma, todo el universo narrativo se ambigüiza. Cualquier voyeurismo en la obra de Mora resultaría en un flagrante fiasco. En ella hay una constante tension (por cierto buscada y exhibida por el propio productor del texto) que proteje y oculta al escritor mediante la ambigüedad de que lo que ha sido dicho por él puede ser él, pero puede no serlo. La creación de Polo Moro y su liberación es la mejor coartada.

Determinada por una ficcionalización que no se avergüenza de sí misma, su obra no oculta su naturaleza: es sólo una simulación, repite a cada paso, verosímil tal vez, pero simulación al fin y al cabo. Por eso, en cuanto al contexto y los niveles de verosimilitud correlativos, su ficción se autodefine en La Película (otro de sus relatos publicados por la Editorial de la Universidad de Costa Rica), como una leve sombra de la realidad; la realidad, advierte el texto, es siempre más cruel y más grotesca que lo que usted logre leer en él. Perdón, "grotesca" es una palabra que Mora no permite, no me acepta, he convenido con él - posibilidad que da la amistad que media, debo admitirlo honestamente- en sustituirla por la de "tremendismo" cuando me refiero a su obra, sólo para calmarlo.

La verosimilitud, según se tiene establecido hasta el momento, no se detecta en términos de equivalencias reales, sino en índices de coherencia y cohesión. Esa coherencia y cohesión es la significación, el sentido logrado, que no es otra cosa que una tercera realidad colocada por encima de las contradicciones detectables en un texto. Este el único pase de abordaje en el mundo ficcional de Mora, cualquier otro procedimiento no nos llevaría al destino prometido porque estaríamos tomando el vuelo equivocado. 
Esa idea de lo verosímil es el tranquilizador tul detrás del cual Mora se desnuda y desnuda a nuestro cuerpo policial, a nuestro cuerpo médico, a nuestro cuerpo diplomático, a nuestro cuerpo de profesores, a nuestro cuerpo de críticos...en fin a todo nuestro cuerpo social y... se desnuda a sí mismo.

Escribir es desnudarse, dice Mora, pero no le ha bastado eso. Después de que con la punta de su pluma se fue despojando a lo largo de dos décadas de todos sus trapos, se expone a la plumilla de Miguel Hernández para que no se tenga ninguna duda sobre su desnudez, para que nadie dude de que lo único que se ha dejado para seguir escribiendo, son sus anteojos.

Por eso Mora es un odioso y da envidia; Mora es odioso porque no he conocido a otro que sea tan él mismo como lo es él; porque él ha logrado lo que para muchos de nosotros sigue siendo apenas un proyecto: la aspiración de llegar a ser lo que uno es.

Mora se quitó la ropa delante de Miguel Hernández y se sentó dos horas en un banco para que Miguel lo pintara y así exponerse ante sus congéneres, una vez más, de otro modo, en toda su rotunda desnudez. Este gesto de Mora es un acto de soberana insolencia, insolencia que solo la da precisamente la soberanía que se han ganado -a pesar de todo y contra todo- los libres de espíritu.

Mora se vuelve a reír, se ríe una vez más porque él sabe que va a molestar a muchos.

¿Es usted uno de los que se molestan? Por qué se molesta usted? Mora, el odioso, se ríe porque le encanta provocar, pero al mismo tiempo se pone muy serio y me escribe:

"Para mí fue una experiencia casi mística: verme nacer de la nada. El trabajo le tomó (se refiere a Miguel) cosa de dos horas. Cuando acabó estaba exhausto, sudando. Y yo también. Acabé con el culo y las piernas dormidas. Fue impresionante verme nacer en el papel. Porque no puedes negar que soy yo o lo que queda de mi cuerpo. Siempre he creído que hay un reto supremo para el pintor y otro para el escritor. Para el artista plástico: el cuerpo humano. Para el que escribe: la psicología, el mundo psíquico del personaje, sin ese bagaje ningún personaje se levanta de la página."

Así es Mora. Así no es Mora. Todo eso es Mora. Perverso, carnal, sarcástico, romántico, enamorado, sensible; desenfrenado y contemplativo; lascivo y místico. Siempre eterna y crónicamente disidente.

"No puedes negar que soy yo o lo que queda de mi cuerpo ", me escribe; subrayo la palabra "cuerpo". Si observamos la pintura de Hernández, de ese cuerpo desnudo penden todavía del cuello los anteojos, suspendidos de su eterno cordón en el pecho del autor. Los anteojos, metonimia del oficio del que escribe, del que fabrica signos, signos que no son otra cosa que el cuerpo ideológico de su sociedad, la conciencia cultural.

Y ahora que no está Mora puedo seguir hablando del grotesco de su obra. Creo que Mora rechaza el término porque pesa sobre él un estigma, una marca negativizante. En efecto, muchas de las formas de lo grotesco moderno no son más que un modo de expresar lo extraño, lo inhumano. Nada más contrario al propósito de Mora. El grotesco moderno es por eso escéptico y vacío de significación. Mora no quiere verse confundido con semejante estética, porque la suya es muy otra. Su "grotesco" no es ni fragmentario ni negativo, sino liberador y optimista. Su grotesco es una derivación del carnaval, entendido de una manera genuinamente bajtiniana .

Lo grotesco bajtiniano carnavaliza, suspende el orden del cuerpo social porque se opone a la norma y a la autoridad. Festeja el exceso y lo antidogmático en el encuentro de los cuer- 
pos en las copulaciones, placeres, lujurias, gestos, defecaciones. En él predomina el juego, la risa irónica o el llanto carcajeado, la contradanza entre el cuerpo y el mundo; revela los excesos regeneradores de una política libidinal que libera. Eso es lo que explicaría el erotismo en la obra de Mora, su trasngresión escatológica y sexual, los elementos escandalosos, subversivos y antisociales.

En las obras de Mora el erotismo no es gratuito, si lo fuera sería mera pornografía. Su erotismo más bien obedece a una descripción libidino-política del cuerpo, que refracta un proceso ideológico de formación y expresión. En esa presencia de lo libidinal se asientan los mecanismos del sentido, la virtualidad de llevar la siginificación a una dimensión estética. La cohesión, la coherencia de su escritura, se amasa en esa tercera realidad a la que aludiamos hace un rato, por encima de cualquier contradicción o mala fe. En ese nivel tercero cada elemento de sus textos obedece al mismo propósito.

La somatización y semantización del cuerpo explicaría, por ejemplo, la oralidad del estilo narrativo de Mora, pues es el registro que más se familiariza con el cuerpo; ya que en la oralidad, la voz humana en sí misma, los gestos y la expresión corporal en general, se convierten en signo. Si se va a expresar el cuerpo, la oralidad es el lenguaje del cuerpo y este lenguaje refracta la ideología: lenguaje abusivo, imprecatorio, insultante y poliglótico porque es voz de las culturas marginadas o subordinadas. Mundo de la heteroglosia social: del travesti, de la prostituta, de la lesbiana, del gay, del drogadicto, del médico, del enfermo, del loco, del burgués, del crítico, del profesor, del estudiante, del joven, de la salonera, del cantinero, del turista, del extranjero, del emigrado, del político, del pulpero y del vecino.

Mora no es de esos futuristas posmodernos, a pesar de su incansable entusiasmo por la experimentación formal. Mora no presenta, como ellos, una negación radical del pasado, todo lo contrario, la mayoría de sus historias son memoriales. Esta peculiaridad, más el interés por la marginalidad y la subsiguiente búsqueda del sí, quizá se deban a su experiencia del destierro. Ambos tonos anímicos, el de la nostalgia y el del extrañamiento, ya lo hemos visto en innumerables ejemplos de la literatura del destierro en este continente, son los dos síntomas más severos del síndrome del exilio. El presente de Mora se crea sólo a partir de la recuperación del pasado. El significado del título del libro que presentamos hoy es más que elocuente en relación con lo que estoy afirmando: La distancia del último adiós es un recorrido de espacios y temporalidades en los que ocurren eventos, cambios, transformaciones que originaron la instancia y el instante mismo desde el que se nos habla y hablará en toda su obra, pues la distancia del último adiós, es una obertura, un conjunto de cortometrajes prologales de lo que será el largometraje de su obra posterior.

Es en el curso mismo del recorrido de esa distancia que se da el crecimiento del sí mismo, de esa subjetividad de la que hablábamos al principio de este comentario, su verdadero tema, su intención de escritor, el factor fijado como meta: la psicología del personaje, dice él, la creación de una conciencia tan verosímil que logre levantar al personaje de la página, digo yo. Experiencia positiva, experiencia del vivir, experiencia del ser, a pesar de la Enfermedad Mortal, título de otra de sus novelas; pues no se trata, para el ser, de la renuncia del sí, sino más bien de la aceptación de sí y de la reconciliación con todos.

Alcanzado a través del viaje memorial de la recuperación del pasado, el presente es momento de apofansis y hierofanía, de revelación y júbilo, porque es el instante de la presencia, del 
encuentro y de la relación. La presencia nace cuando el tú se hace presente, pues el yo no confrontado por un tú no tiene presente, sólo pasado. Es en el momento en que el sujeto hace la experiencia de sí mismo que se da el instante realmente presente y pleno. Ese es precisamente El final del comienzo, como dice el título de una de las dos novelas mejor logradas de este autor y en la que se da el inicio de una proximidad feliz a la muerte, la mortal enfermedad. Finalizado el comienzo, el aprendizaje del cómo vivir, lo que sigue es vivir . El sentido de la vida no pide ser interpretado, dice Buber, sólo actualizado, pues el sentido de la vida sólo es confirmable en la propia vivencia de este instante en que me sé vivo. El sentido de la vida no es el sentido de otro instante, de un más allá, sino el de mi aquí y ahora, de mi presencialidad. En eso reside la intensidad de Mora. "La vida, María -me ha dicho Mora- dura lo que tarda un pestañeo. Vive el instante, María".

Ni escepticismo ni fragmentación. No encontramos en la obra de Mora la fragmentación grotesca de la forma posmodernista; todo lo contrario, lo que encontramos es totalidad y asimilación. La apofansis, la revelación del yo es dolorosa, porque a pesar de la risa (por eso es una risa irónica), es un yo que se acusa y que confiesa. Pero ese yo envilecido se reivindica pública y positivamente justamente en el acto mismo de esa confesión y en la aceptación del sí mismo: liberación de la sombra de la culpa que lo ha perseguido y que ha sido desde el inicio ( sólo entonces nos enteramos), la motivación primera de la escritura. Terapia de la depresión. Transformación del conocimiento que le descubre que es precisamente en la libertad que había elegido y en su movimiento, en su proceso de mundanización, que él encontró su destino: ser lo que es, y que no se puede renegar de uno mismo, tan sólo conocerse para poder seguir moldeando, siempre en el curso de la vida y la historia personal, lo que somos y no hemos logrado ser.

Dice Buber que sólo el hombre que hace de la libertad algo real para él, encuentra el destino. Por eso la literatura de Mora es una construida sobre la rebeldía, a base de transgresiones políticas y literarias. Construida sobre una libertad perceptiva que tiene un significado político, revolucionario: regenerar, reeducar en un proceso de individualización liberado de toda cohersión que impida su despliegue.

Visto así, lo "grotesco" de Mora no puede ser un calificativo negativo, desmerecedor, porque no es sinónimo de simple perversión u hostilidad, sino que es la expresión de un proyecto libertario, crítico-ficcionalizador, memoria subterránea de la sociedad, caja de resonancias de los cambios sociales e ideológicos que vivimos pero que no son necesariamente perceptibles para todos, sólo para aquellos en los que el pensar de otro modo es condición primera en toda creación de libertad.

Pero ya es hora de callarme, hablemos de este libro, hablemos de La distancia del último adiós y comencemos a explorar un genuino laboratorio del arte de narrar, al tiempo que penetramos en el laberinto que debe recorrer un yo para hacerse ingobernable dentro de las tecnologías manipuladoras de la subjetividad, para redescubrir en sí mismo al șer humano real que él es, como verdad inmediata e intemporal.

\section{Bibliografía}

Duber, Martín, Tú y yo. (s. d.)

Dalton, Cristina. 1990. Lengua y literatura. San José: EUED. 
Focault, Michel. 1983. The Technologies of the Self. A Seminar with Michel Foucaul. Massachussets: Luther. H. Martin. 1986. El uso de los placeres. México: Siglo XXI. 1987. La inquietud de sí. México: Siglo XXI.

Mora-Amoretti. Correspondencia faxilar. Archivo personal de la Dra. María Amoretti.

Todorov, Tzetvan. 1981. Mikhail Bakhtine. Le principe dialogique. Suivi de Ecrits du Cercle de Bakhtin. París: Seuil.

Zavala, Iris. 1991. La Posmodernidad y Mijail Bajtin. Madrid: Espasa Calpe. Tr. Epiceto Díaz Navarro. 